\title{
ELIODORO PUCHE, UN RARO Y OLVIDADO ENTRE SIMBOLISMO Y VANGUARDIA
}

\author{
Francisco Javier Díez DE RevengA \\ Universidad de Murcia
}

De más edad que la mayor parte de los poetas ultraístas españoles, Eliodoro Puche, que nació en Lorca (Murcia) en 1885, estudió Derecho, aunque apenas ejerció la carrera, y de forma interina, durante la guerra civil, como juez de paz y notario. Vivió en Madrid años de llamativa bohemia, escandalosa, espectacular y especialmente pintoresca, y fue de los primeros en adscribirse a las empresas de la vanguardia, en cuyas revistas colaboró. Sus contemporáneos cuentan multitud de pintorescas aventuras de la etapa madrileña de Puche. Poeta inicialmente simbolista, buen traductor de sus maestros franceses, fue ultraísta y tras su regreso a Lorca, poeta social y posromántico de irregular inspiración. Tras la Guerra Civil, fue encarcelado y, reintegrado a la vida civil, vivió retirado en Lorca donde murió en 1964.

Sus obras más destacadas son: Libro de los elogios galantes y los crepúsculos del otoño (Tipografía Yagües Madrid, 1917), Corazón de la noche (Tipografía Yagües, Madrid, 1918), Motivos líricos (Tipografía Yagües, Madrid, 1919), Colección de poemas (Imprenta Mínguez, Lorca, 1936), Poemas inéditos (Centro Cultural Narciso Yepes, Lorca, 1961), Las alas en el aire. Ficción poética de El marinero de amor. Otros poemas (Obra Cultural CajaMurcia, Murcia, 1989). Ha tenido varias ediciones críticas de sus obras y una escogida bibliografía ha destacado sus valores.

La incorporación de Eliodoro Puche al arte de vanguardia es total en torno a 1920 y hay ejemplos de esta entrega muy célebres como el poema «Silencio». Desprovisto de cualquier anécdota, carente de argumento o tema racional o humano, está compuesto, sin embargo, sobre la base de 
imágenes, de emociones creadas que pretenden trasmitir su sentido de una manera plástica. La configuración caligramática representa con claridad la verticalidad y certeza de un gesto que lo que pretende comunicar es una sensación de quietud y de «silencio», definitivamente impuesto en la imagen final del reloj con el dedo en la boca, que trata de expresar al captar el peso y la verticalidad de una plomada. El poema aparece publicado en el número de octubre de 1920 de Cervantes y en el número 11, de 20 de mayo de 1921 de Vltra. Sobre él hemos de volver.

Otras composiciones suyas, publicadas en las revistas de vanguardia, ofrecen perspectivas diferentes de su cultivo del ultraísmo: en «Noche», que trata uno de los temas preferidos del poeta, la noche, ofrece ahora esa representación bajo una imaginería muy distinta. Aunque sin perder del todo la presencia de los términos reales que inspiran al poeta, la fuerza e independencia de las imágenes, hacen que éstas predominen y se produzca el desequilibrio entre el mundo real y la imagen propia del ultraísmo y del creacionismo. Las imágenes se basan en impresiones aisladas de luz o de color. Las figuraciones míticas son herencia del simbolismo que Puche practicó con asiduidad a lo largo de toda su obra. El poema se publica en Cervantes, en octubre de 1920 y en Vltra en el número 13, 10 de junio de 1921. Más adelante nos referiremos a él detenidamente.

Pero antes, vamos a recordar poemas de Eliodoro Puche absolutamente olvidados, y encuadrados en la más temprana vanguardia, ya que aparecen publicados en la revista Grecia en 1918, cuando esta revista, recién inaugurada, se publicaba aún en Sevilla, y en 1920, cuando ya se publicaba en Madrid. Y es que la revista Grecia fue sevillana en su origen, aunque sus últimos números se publicaron en Madrid, porque a esta ciudad se había trasladado a vivir su director, Isaac del Vando-Villar, uno de los más interesantes ultraístas españoles y de gran significación histórica en el desarrollo de la vanguardia, sobre todo por haber logrado mantener la revista a lo largo de tantos números. El último de los números de la revista incluyó un «manifiesto vertical», de Guillermo de Torre. La revista comenzó siendo modernista, con aires decadentes y parisinos que se advertían incluso en la ilustración de su portada en los primeros números, aunque pronto cambió esa cubierta y propuso en ella un ánfora griega que en algunos números apareció acompañada de una lata de aceite para automóviles. La evolución de las portadas marca bien el espíritu innovador que fue introduciéndose poco a poco en la revista.

Uno de los aspectos más destacables de esta publicación es la gran cantidad de colaboradores que en ella participaron, y que procedían de distintos frentes vanguardistas. Desde luego, el más numeroso era el grupo sevillano de escritores y sobre todo de poetas vanguardistas, entre los 
que destacaron Rogelio Buendía, Luis Mosquera, Pedro Raida, José María Romero, Miguel Romero Martínez, y, sobre todo, Adriano del Valle. Es también muy nutrida la presencia de los ultraístas madrileños, sin duda conectados con el grupo sevillano por Rafael Cansinos Assens, que firmaba sus poemas con el seudónimo de Juan Las.

Entre los de este grupo figuran los más sobresalientes nombres del ultraísmo español, como Xavier Bóveda, José de Ciria y Escalante, Pedro Garfias, Gerardo Diego, César Comet, Evaristo Correa-Calderón, Juan Larrea y Guillermo de Torre. Entre los poetas del 27, hallamos además de a Diego, a Federico García Lorca, que sólo publicó un texto en prosa en la revista, a Dámaso Alonso, escondido con el seudónimo de Ángel Candiz, y a Vicente Aleixandre, también escondido con el seudónimo de Alejandro G. de Pruneda. Igualmente figuran otros personajes curiosos como el escritor lorquino Eliodoro Puche o el gran don Ramón del Valle-Inclán que hace sus pinitos poéticos ultraístas, por más que pueda sorprendernos.

Pero más sorprendente, hoy, es la presencia de Jorge Luis Borges, que publicó aquí los primeros poemas de su vida y algún relato sorprendente y que fue asiduo colaborador como su hermana la pintora Norah Borges, que se casaría con Guillermo de Torre, posteriormente.

Una de los aspectos que más llaman la atención de Grecia, y que sin duda aumentan su valor como representación histórica de un momento cultural único, es la presencia de escritores extranjeros, fundamentalmente franceses, entre los que hallamos nombres tan representativos como Guillaume Apollinaire, Louis Aragon, André Breton, Tristan Tzara, Pierre Reverdy, Blaise Cendars, Max Jacob y otros muchos. Por supuesto, también estuvo presente el importantísimo Ludovico Tomasso Marinetti, creador del futurismo.

Los poemas más antiguos publicados en Grecia los da a conocer Eliodoro Puche en el número 2 , de $1^{\circ}$ de noviembre de 1918. Son tres composiciones, acogidas bajo el título común de «Motivos líricos», y es que los tres textos pasarían a formar parte de su libro, de 1919, Motivos líricos. Se titulan respectivamente «Amor», «Noche» $\mathrm{y}$ «Plenitud», tres poemas perfectamente adscribibles a un tardío simbolismo, que del mismo modo caracterizaba a la revista en sus más antiguas entregas. Así lo podemos advertir en los motivos del poema «Amor»:

La hermosa cayó de las estrellas como una luz, nos dijo su secreto:

... Yo soy toda la luz,

Y un corazón cayó en el nuestro.

El alma de la noche

flotaba en los espejos. 
Venían en corceles de oro

los caballeros

que traían las rosas

de los ensueños...

Y ella tenía

la claridad celeste de lo eterno.

El segundo poema, «Noche» es característico del Eliodoro Puche más genuino, al construir un perfecto nocturno, a los que su poesía simbolista estaba tan acostumbrada. Los motivos son los habituales: el silencio, la luna, el alma... aunque representada en una actitud diferente, como distintas son también las sensaciones olfativas y acústicas que acentúan el mundo simbólico del pequeño poema, incluido ese «ignotiza», sin duda errata, por «hipnotiza».

En el silencio nocturno

la soledad de mi drama.

La luna nos mira

-Tienes

luna una sonrisa falsa.

El recuerdo por caminos

de luz retorna a mi alba:

por senderos de perfumes

el olfato se me escapa

y el horizonte de amor

ignotiza la mirada.

En un pájaro del bosque

está cantando mi alma.

El poema es característico de esta época decadente de Eliodoro $\mathrm{Pu}-$ che, que desarrolla su muy personal interpretación del modernismo con no menos rebuscadas representaciones sensoriales que van más allá de la tradicional sinestesia. Quizá lo más personal de este poema es su gran pasión irredenta de amante de la luna. No es extraño que Grecia acogiera este poema en sus páginas en este año de 1919, ya que la revista no ha sufrido aún su transformación ultraísta.

Más pequeño poema aún, dada su brevedad, es la tercera composición, en donde las imágenes reflejan la convergencia de vanguardia y simbolismo:

Están los días en primavera

y la emoción es una escala 
por donde sube al cielo

la mariposa de mi alma.

De un alcance indudablemente superior son las dos colaboraciones que publica en 1920 en Grecia, hoy totalmente olvidadas ya que no serían recogidas en ningún libro posterior por Eliodoro Puche. La primera aparece en el número 46 , de 15 de julio y está formada por tres composiciones unidas por el título común de «Mundos de cristal», bajo el epígrafe muy significativo de «Poema del Ultra». Está dedicado a Ramón Gómez de la Serna, y, como es habitual en Eliodoro Puche, combina elementos típicamente simbolistas con imágenes mucho más agresivas procedentes de la primera vanguardia. Así, en el primer poema hallamos elementos de la naturale$\mathrm{za}$, del paisaje, junto a las habituales referencias al intimismo simbolista (alma, corazón, idea...) mezclados con imágenes más atrevidas. Junto a la mención de Afrodita encontramos metáforas como «edredón cinéreo», «labios de nácar»:

Camino del horizonte trémulo

mis alas

perdieron

todas sus plumas,

sus plumas blancas...

Y sobre el edredón cinéreo

duerme mi mejor palabra,

hasta la muerte de mi alma.

El cielo bajo el mar...

En la noche se eleva

el cántico

de sirena,

que hace a los astros naufragar.

Fondo sediento de la dicha celeste...

Estrella,

perla

y coral,

sangre de sol pensativo.

Entre los labios de nácar

(como sexo virgen) de un hermoso molusco,

mi corazón,

siente el color de la espuma,

carne de Afrodita. 
Palabra mía...

cuerpo vivo de mi idea...

que mañana,

allá, a la muerte de mi alma,

tu locura crepuscular

se alce

sobre mi tierra carnal,

sol

de mi sombra

corazón.

El segundo poema, mucho más breve, responde también al concepto simbolista de «motivo lírico», ya que se trata de un fugaz nocturno (tan queridos de Eliodoro Puche) en el que la atmósfera de ensueño lo es todo en el poema:

Sonríe la luna

tras una nube opaca...

Un pájaro invisible estrellas vivas

dora en el cielo cuando canta.

Sendas de aromas

suben a las ventanas...

Por ellas,

una voz femenina, viaja.

Y, finalmente en el tercero, asistimos a un dinámico crepúsculo muy sensual, encuadrado plenamente en la expresión modernista:

Has dejado en la tarde

el cuadro de la dicha...

La rosa del ocaso

ha perdido su vida

al caer en el fondo

verde, de tus pupilas....

Crepúsculo,

entre beso y sonrisa

¡tu boca!...

Y en ella, el alma fugitiva, tiemble un momento, herida. 
Pone la noche

nuestra carne sonora de caricias...

nuestra carne que sabe

la música infinita

del último silencio

que la pone marchita.

Llueven estrellas

en el espejo de la fuente limpia...,

y sobre el césped luminoso,

hay desperezos de la brisa.

¡Quién deshojará mis canciones

enrojecidas

sobre las rosas blancas!

Posa tu mano amiga

en mi deseo muerto

por ver si resucita.

Transcribimos ahora el poema aparecido en Grecia, en el número 48, de 1 de septiembre de 1920, en el que volvemos a recuperar al Eliodoro Puche más próximo al modernismo bohemio que él practicaba en el Madrid de finales de la década, cercano a Emilio Carrere, su maestro en estos momentos. Obsérvese la condición rupturista de algunas imágenes y lo sorprendente de la retórica expresiva de este poema: nubes preñadas de llanto, ciprés de sol, el barro de mi espíritu; junto a las referencias sensuales: carne de fuego, rosas de pecado; y las inevitables alusiones a la tecnología y al mundo moderno, de origen futurista, que anunciaban ya la vanguardia más agresivas: ojos fotográficos...:

Primavera

en esta cumbre de la tierra...

... Y un ruiseñor divino

en mi corazón canta.

Alegría

y tristeza, abrid las ventanas.

Ya,

las nubes preñadas de llanto 
todas sus lágrimas

lloraron...

Y una esperanza

tendida

en su propio regazo,

como un ciprés de sol, eleva

su ángulo en el vacío,

lo mismo

que la punta de un rayo

de luz

en el alma de un zafiro.

Amada...

Amor...

Tentáculos del corazón

del barro de mi espíritu, de la luz de tu barro

y de mi barro...

Amada...

¡Palabra!

¡Palabra

sin alas!...

Y

hasta en ti

el mármol de la Venus

se hizo carne

en tu carne de fuego;

$\mathrm{y}$ en tu insulso

rostro de virgen

se abren

tímidas rosas de pecado.

Frente, casi sin pensamiento,

frente matinal

cubierta de rocío de besos

de los besos...

Pétalos vivos

-labios-

frutos heridos 
de la muerte más dulce

leyes vespertinas-.

Y tu cuerpo

en mediodía...

Y tus ojos fotográficos

de locuras hermosas...

La primavera

en irrupción...

y en fuga...

¿Qué es eso

que por los cielos abiertos

cruza?

No son menos interesantes los poemas vanguardistas que Puche dio a conocer en la revista Vltra, una de las más inconformistas de la vanguardia hispánica, que había aparecido en Madrid entre 1921 y 1922, y que reúne todas las condiciones características de las revistas de los movimientos revolucionarios de los primeros años veinte. Fue efímera en su existencia (tan sólo veinticuatro números en poco más de un año) y agresiva en su diseño futurista. No tenía director porque su condición dadaísta así se lo impedía, pero en ella colaboraron, gobernados por Humberto Rivas Panedas, cuantos peregrinos poetas comulgaban con el movimiento ultraísta: Gerardo Diego, Adriano del Valle, Luciano de San Saor, Pedro Garfias y hasta los más jóvenes: Luis Buñuel, Rosa Chacel, etc.

La revista Vltra supone una minoración y moderación de los afanes caligramáticos, aunque desde el punto de vista plástico es una de las más hermosas revistas de la vanguardia española, debido a los dibujos que todos sus números contenían. Los textos en ella recogidos adoptan disposiciones tipográficas caprichosas, pero sin llegar al caligrama total. Agrupaciones paralelas de versos, sangrados diversos, estructuraciones en bloques, desarrollos enumerativos, encuadramientos de palabras significativas, combinaciones de palabras en versales y en caja baja, juegos de espacios, estructuras contrastadas, desplazamientos de frases, reiteraciones de formas externas, son algunos de los procedimientos que constituyen la dirección que, a partir de 1920, va a seguir toda la poesía de vanguardia.

Cuando los jóvenes ultraístas, seducidos por las novedades que venían de Europa, de Suiza (dadá), de Italia (futurismo), se lanzan a romper las barreras de lo racional y lo coherente en busca del arte nuevo, Puche avanza con ellos, y se convierte bien pronto en un aventajado ultraísta. Ahora, al 
publicar la inencontrable revista Vltra, gracias a que se ha podido reproducir la colección particular de Gerardo Diego, descubrimos a un Eliodoro Puche militante y entusiasta, respetado por los responsables de la revista, que situaban sus poemas y sus magníficas traducciones de los franceses, en lugar preferente, decidido propulsor de un movimiento revolucionario, el ultraísmo que se extinguió muy pronto, bien es cierto. Pero entre los españoles ya estaba sembrada la semilla de la subversión artística, del inconformismo y de la revolución literaria. El camino para que triunfara el creacionismo, y, sobre todo, el gran surrealismo literario español, ya estaba allanado. El controvertido Eliodoro Puche, en su modestia, en su disparatada personalidad, allí estaba en primera fila, como uno más, como el más agresivo y avanzado vanguardista.

Como ya sabemos, por mi estudio de 1980, al que remitimos, Eliodoro Puche participó en las otras revistas más famosas de la vanguardia. En Los Quijotes, en Grecia, en Cosmópolis y en Cervantes, entre otras. Y, al mismo tiempo que las citadas revistas, Puche evolucionó desde un postsimbolismo modernista, neobarroco y recargado, hacia el arte de vanguardia, y, en concreto, hacia el ultraísmo. Produjo algunos poemas encuadrables en este movimiento, y, muy pronto, como ocurrió con los restantes poetas de este movimiento, reconvirtió algunas de estas poesías y las hizo simbolistas. El resto las olvidó y no las reunió en su siguiente libro, como había hecho con las de 1917 y 1918, que había incluido en Corazón de la noche y Motivos líricos. Todo ello está explicado en mi libro de 1980, y a él me remito. Pero ahora, al aparecer la revista Vltra, que, como hemos dicho, era inencontrable, y yo no pude consultar en los años en que escribí el libro de 1980, aparecen cosas muy interesantes y curiosas, que sin duda han de llamar la atención del lector que conozca un poco la vanguardia.

A continuación, vamos a reproducir todos los poemas que publicó Puche en Vltra, y, tras ellos, vamos a llevar a cabo algunas anotaciones que me parecen de interés. Dejamos sin reproducción ni comentario una traducción de Baudelaire, que Puche publica en el número 8, de 20 de abril de 1921, y que ocupa toda una página, lo que pone de relieve el respeto que tenían los gestores de Vltra hacia Puche. Se titula «Carlos Baudelaire (Con motivo de su aniversario). El viaje».

Comenzamos por el titulado «Mundo de cristal», publicado en el número 4, el 1 de marzo de 1921:

Escucho el eco de mi voz devuelto por los cuatro horizontes del silencio.

En el fanal maravilloso, alguien pinta la emoción de un hermoso día. 
Mi sueño, demasiado real, había hecho de una flor una mujer, sólo para mis labios puros. También había poblado las soledades con una utopía candorosa, pretérita y extática.

Sin embargo, trepidan engranajes, suenan clarines, ayes y lágrimas, de pronto.

Pájaros de acero, brotan de los mares, cantan cerniéndose en la atmósfera y llevan el sol enredado en sus alas.

Se trata de un poema en prosa, o en versículos extensos, que podemos considerar medianamente ultraísta o de transición. Todavía se advierten restos muy notables de la etapa anterior, aunque aparecen ya gestos nuevos, de origen futurista («Engranajes», «pájaros de acero») junto a atrevidas imágenes irracionales, netamente ultraístas, y relacionables con la greguería de Ramón Gómez de la Serna («llevan el sol enredado en sus alas»). Como vemos, todos estos elementos vanguardistas lo que vienen a hacer es interrumpir el mundo de ensueño de la primera parte, en el que residían elementos idealistas: el horizonte, la mujer, la flor, «un sueño demasiado real».

El segundo poema aparece con el epígrafe de «Poemas en prosa»y se titula del mismo modo «Mundos de cristal», como si perteneciese a una serie de poemas de este tipo, que Puche debería de tener coleccionados o coleccionables. Se publica en el número 5, de 17 de marzo de 1921.

Alguien laminó el mar y es un enorme reverbero.

En el crisol del oriente se funde un nuevo día.

Mi corazón tan verde en otras estaciones, este verano maduró como un fruto del trópico.

-Mírame como el sol... Dime tus palabras más rojas.

Era otro estío.

Entre hoy y ayer hay un desierto...

Blanco donde va la flecha de mi memoria... Venero de mis aguas nuevas.

¿Quedó tu ánfora colmada de mí?...

¡Dime hoy cuanto callaste entonces!

¿Nuestro espejo perdió su fondo y no quiere copiarnos ya?... Sin embargo mis ojos aún contemplan la hermosura...

...Y los tuyos ¿verdad? en donde flota tu corazón de luz.

El título de «Mundos de cristal» lo había utilizado Puche para reunir tres poemas que publica el año anterior en la revista Cervantes, en el nú- 
mero de octubre de 1920 (Recuérdese que Cervantes no numeraba sus entregas de revistas). En mi libro de 1980 doy cuenta de ello y a él me permito una vez más referirme. Sobre alguno de estos «Mundos de cristal», es decir, sobre alguno de estos poemas, hemos de volver. Respecto a la evolución de Puche, hemos de considerar este poema nuevamente de transición, con motivos simbolistas e imágenes ultraístas conjuntadas en un mismo contexto.

En el número 7, de 10 de abril de 1921, figura una nueva entrega de la serie «Mundos de cristal»

De las cenizas del sol irradia una noche de plomo.

-Es mucha primavera para nuestra carne cansada.

-Mi cabeza en la nube descansaría... ¡Ay!... Me aburro.

-Tú tienes siempre razón.

La selva de la ciudad cristaliza en la sombra.

Los mares cuelgan del vacío y extrañas estelas cruzan el cobrilleo casi imperceptible. Al horizonte un faro... Y una voz:

-iiiCuidado, celestes marineros!!!

Unos brazos se desperezan al ritmo de un bostezo... Un grito después.

-Ya te dije que no abrieras los ojos, morena roja. Tu hermana, la luna, se maquilla ante el espejo como una jovenzuela que soñara en el novio.

-Es cursi romanticismo... a sus años... Me aburro.

-Tú siempre tienes razón.

Nuevamente, un poema en prosa, impregnado de gestos ultraístas, nos muestra al Eliodoro Puche de vanguardia cercano, como siempre, a la greguería ramoniana, y con un sentido del humor emparentado con algunas de las actitudes de los movimientos avanzados. Aun así, todavía no consigue despegarse de sus modos fantástico-idealistas, próximos a las evocaciones de bohemia. La referencia final al romanticismo, cursi, no deja de ser igualmente significativa y combina perfectamente con los hallazgos ultraístas del comienzo del poema ( «La selva de la ciudad cristaliza en la sombra») y de sus «versos» interiores: la luna maquillándose como una jovencita no deja de tener gracia.

En efecto, estamos ante un relato vanguardista neto y puro, sin argumento, con su narración, descripción y diálogo, sus personajes, pero sin progreso episódico alguno, reflejo de un hastío, de un aburrimiento, muy de época, muy de esa generación. La fértil y peregrina pluma de Eliodoro 
Puche, que asoma de vez en cuando a las páginas de las revistas de vanguardia, sorprende con este relato tan nítido, tan sin elementos, escena fragmentaria total, recortada de un cuadro romántico amoroso, como, desenfada y serenamente, se denuncia y anuncia en el mismo relato.

No faltan, en las descripciones las imágenes ultraístas, como ese despliegue que abre el texto, entre cenizas y plomo, o esa selva de la ciudad que se cristaliza en la sombra, o mares colgando del vacío mientras cruza extrañas estelas. La luna maquillándose en el espejo como una jovenzuela es otro de los hallazgos singulares de la calenturienta imaginación de Eliodoro Puche, genio y figura en este texto como en todas y cada una de sus colaboraciones en las revistas de vanguardia.

Quizá Eliodoro Puche estaba convencido de los que los ultraístas manifestaban en la revista, número 9 del 30 de abril de 1921: «Propugnamos una antiliteratura implacable, devastadora de todas las topificaciones arraigadas. Ya hemos afirmado que «la literatura no existe: el ultraísmo la ha matado». De ahí el título de nuestra próxima encuesta, dirigida a jóvenes y viejos profesionales: «¿Por qué escribe usted AÚN?»

En el mismo número 9, de 30 de abril de 1921, publicaron a Puche un poema interesante, titulado «Primavera»:

\author{
Los frutos del sol \\ esta primavera \\ no maduraron. \\ Tu hermosura aleja \\ los horizontes, de mi deseo. \\ Aquella barca que no naufragó \\ está perdida. \\ No hay que hablar de amor \\ ¡ya! \\ Los espejos sin luna \\ no sabrían copiar nuestro abrazo. \\ ¡Eres demasiado bella!
}

Nuevamente, Puche se nos refleja como un poeta de transición, y otra vez combina hallazgos ligeramente irracionales con la elucubración idealista, entre romántica y simbolista, de acuerdo con lo que es normal en él en este momento.

Los ultraístas hacían cosas muy raras, y los lectores de sus revistas habrán visto singularidades llamativas. Una revista no suele publicar un original de un autor nada más que una sola vez. Pues bien, los gestores de 
Vltra contravinieron esta norma no escrita, porque un poema en prosa de Eliodoro Puche, incluido en el número 10, de 10 de mayo de 1921, titulado «Recuerdo», y cuyo texto reproducimos a continuación, fue vuelto a publicar, algo más tarde, en una versión corregida, y ahora observaremos con qué intención. La primera versión decía:

La tarde fatigada se recuesta en su sombra, y el sol -sauce del horizonte- llueve su deseo flácido y serpentino, lapis-lázuli empurpurado.

En mi memoria, una mujer hermosa se apaga.

En la ruta que desenrollan mis pasos, me sigue siempre el hijo de un amor que no llegó a juntar las bocas.

La segunda versión, aparecida en el número 15, de 30 de junio de 1921, recupera el título común de «Mundos de cristal», que sustituye a «Recuerdo» $\mathrm{y}$ se formaliza como un nuevo texto:

La tarde fatigada se recuesta en su sombra, y el sol -sauce de horizonte- llueve su deseo flácido y serpentino.

Lapislázuli empurpurado.

En el recuerdo, una mujer desnuda se apaga.

Mi ruta se aleja hasta lo imposible.

Me sigue siempre el hijo de aquel amor que no pudo juntar sus labios.

Si disparatado era el poema en su versión primera no lo es menos en la segunda. Mantiene desde luego los hallazgos imaginísticos, pero corrige errores sustanciales que aparecían en la primera versión. Lo del cambio del título, sin duda es para restar romanticismo y anécdota al poema que en su segunda versión queda más aséptico, dentro de lo que cabe.

Y ahora, otra sorpresa por el estilo de la anterior. Los cuatro poemas que nos quedan para comentar, publicados en Vltra, no era inéditos, ya que fueron publicados anteriormente en la revista Cervantes, sin apenas variaciones, como vamos a ver. Pero son los cuatro poemas más ultraístas que escribió Puche, y sin duda uno de ellos una de las muestras más interesantes de la poesía de vanguardia en España, por lo que ha merecido ser recogido en las antologías de vanguardia (3).

Los comentamos, uno a uno, tal como hemos hecho anteriormente. «Silencio», dedicado a José Bances, aparece publicado en el número 11, de 20 de mayo de 1921, con este texto: 
El camino nublado

asciende hasta la cima

del Sol.

Mis pasos

y el aroma de mis primaveras muertas

\section{EL RELOJ}

(Fuga de las horas que caen)

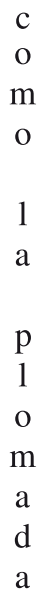

TIENE EL DEDO EN LA BOCA

La versión aparecida en Cervantes, bajo el título conjunto de «Mundos de cristal», y junto a «Noche» y «Epitalamio», se publica en el número de octubre de 1920, con un texto algo diferente, en su disposición tipográfica:

El camino nublado

asciende hasta la cima

del Sol.

Mis pasos

y el aroma

de mis primaveras muertas. 


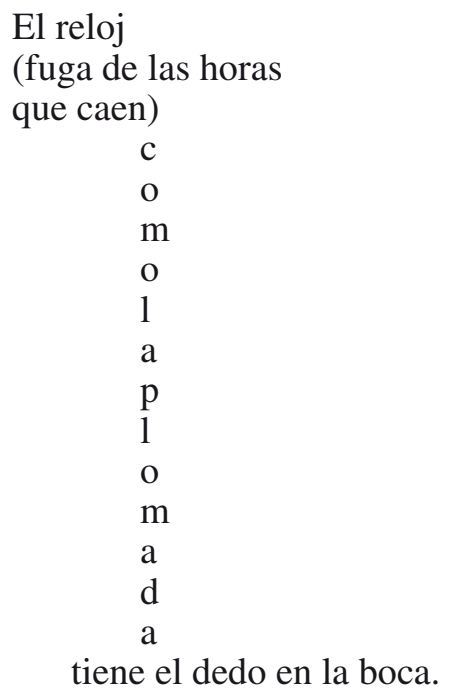

Ya nos referimos detenidamente a este poema en nuestro libro de 1980 en el que destacábamos cómo Puche se había servido de la disposición tipográfica para mostrar uno de los símiles que el poema contiene. La doble versión ha sido tenida en cuenta por Juan Manuel Bonet, quien, a la hora de valorar el poco interés tipográfico de la revista Cervantes, ya que se publicaba sin ninguna ilustración, trae a colación esta doble versión del poema de Puche, que considera «su texto más netamente vanguardista, lo cual tal vez explique que volviera a aparecer al año siguiente, en el número 11 de Vltra, con alguna variante tipográfica» (4).

He aquí el texto de «Epitalamio» que publica Vltra en el número 12, 30 de mayo de 1921:

Puesto que puedes hablar

no me digas lo que piensas.

Tu corazón envuelve

tu carne.

Sobre tu cuerpo desnudo mi voz cosecha palabras. Te traigo de Oriente el Sol para tu anillo de Bodas. 
En el lecho que espera

una rosa se desangra.

En la versión de Cervantes, octubre 1920, tan sólo tenía un blanco interversal más, de manera que el cuarteto del poema se divide en dos pareados. Fue comentado en mi libro de 1980, y considerado de transición, y el más débil del conjunto.

«Noche», aparece en Vltra, en el número 13, 10 de junio de 1921:

\author{
La ciudad \\ ha visto morir al pájaro \\ que la encendía \\ detrás de la sombra de su ala. \\ ¡Qué bien vestida estás de negro \\ viuda de todas las tardes! \\ ¡Qué bien hacen \\ en tu cabeza azul \\ los diamantes! \\ ¡Qué bien hacen \\ los bomberos, \\ Sol, \\ en apagarte!
}

El texto de Cervantes (octubre 1920) es el mismo, con ligeras variantes tipográficas. Blanco entre los versos seis y siete y la palabra sol centrada al verso. «Noche», como escribíamos en 1980, recupera uno de los temas predilectos de Puche, el «nocturno», aunque es evidente que la imaginería de este poema es muy distinta a la de sus representaciones modernistas de este género, donde llegó a alcanzar personalidad notable. El poema es netamente ultraísta y sus imágenes y relaciones de imagen-término real bastante conseguidas.

Por último, «Alba», que se publicó en primera versión en Cervantes en julio de 1920, y en segunda, en Vltra, número 14, 20 de junio de 1921:

Corren mis manos

tras la estatua viva... eterna 
Con sus cabellos encenderá la selva

Cada hoja ardiente vibra como una estrella

Bajo sus pies nacen las rosas -suspiros de la tierra-

En el incensario de Oriente hay matinales humaredas

Se pierde entre las sombras y hacia el alba se aleja

El cielo se ha rasgado...

Es el sol su cabeza

La versión de Cervantes muestra el mismo texto, aunque no tiene los puntos suspensivos en ninguno de los dos casos en que aparecen en la versión de Vltra, que es la reproducida por nosotros. Son sustituidos por un punto. Se trata, es evidente, de un poema más temprano que los anteriores, y, desde luego, de un poema de transición, como dijimos en el estudio de 1980. Lo más interesante es que éste es el poema más vanguardista de los tres que se publicaron juntos en aquel número de Cervantes, de julio de 1920. Mientras los dos primeros, «Estación muerta» y «Mi pipa quema ensueños» son típicamente modernistas o simbolistas, «Alba» refleja un primer irracionalismo muy notable, pero, en todo caso, podemos considerarlo como un poema de transición.

Eliodoro Puche permanecería fiel a la vanguardia durante algunos años, y todavía el 21 de diciembre de 1926, en el periódico La Tarde de Lorca publicaría un poema ultraísta: "Cruza un aeroplano», en el que paga su contribución admirativa hacia los ingenios modernos, incorporando elementos de la vida actual, simbolizados ahora en imágenes tradicionales:

El tiburón del aire que cruzó esta mañana por el azul, traía de otros cielos, en sus aletas, luminosas algas. 
Como un ruiseñor joven, el tiburón mecánico, cantaba sus canciones de hoy, con trinos de mañana.

¡Acaso el tiburón de acero, dormiría en las aguas de la luna

esta noche pasada!

Ha cruzado, como una lanzadera, el tiburón sonoro...

De sus alas

metálicas pendía

zumo de sol en luminosas algas.

Entre simbolismo y vanguardia, a lo largo de esta breve etapa en la poesía de Eliodoro Puche, hemos podido advertir su adscripción, aunque momentánea y muy relativa, sin duda efímera, a los nuevos movimientos poéticos y conocer nuevos datos, y nuevos textos, para el estudio de la obra de este poeta tan singular que fue Eliodoro Puche, cuya obra y todo cuanto rodea su peregrina figura no deja de sorprendernos. 


\section{BIBLIOGRAFÍA}

Barrera, José María (editor), Grecia, Centro Cultural de la Generación del 27, Málaga, 1998.

Bonet, Juan Manuel, Diccionario de las vanguardias en España (19071936), Alianza, Madrid, 1995.

-. (ed.), El ultraísmo y las artes plásticas, IVAM Centre Julio González, Valencia, 1996.

—. «Las revistas madrileñas: del modernismo a la modernidad», Arte moderno y revistas españolas 1898-1936, Museo Nacional de Arte Reina Sofía, Madrid, 1997, pp. 41-51.

Cansinos Assens, Rafael, «Semblanza lírica» en Corazón de la noche, de Eliodoro Puche, Madrid, 1918.

Delgado, Santiago, Literatura en la Región de Murcia, Editora Regional de Murcia, Murcia, 1998.

Díez de Revenga, Francisco Javier, Eliodoro Puche. Historia y crítica de un poeta, Academia Alfonso X el Sabio, Murcia, 1980.

-. «Eliodoro Puche: vida y obra de un poeta», III Ciclo de Temas Lorquinos, CAAM, Lorca, 1982, pp. 13-24.

—. (ed.), Poesía española de vanguardia (1918-1936), Clásicos Castalia, Madrid, 1995.

—. «Nuevos poemas vanguardistas de Eliodoro Puche», Murgetana, 94, 1997, pp. 125-134.

—. La poesía de vanguardia, Laberinto, Madrid, 2001.

- Las Vanguardias y la Generación del 27, Momentos y épocas, Editorial Síntesis, Madrid, 2004.

- Poetas y narradores. La narrativa breve en las revistas de vanguardia en España (1918-1936), Devenir Ensayo-Fundación Gerardo DiegoCentro Cultural de la Generación del 27, Madrid, 2005.

- y De PaCo, Mariano, Historia de la Literatura Murciana, Universidad de Murcia. Academia Alfonso X el Sabio. Editora Regional de Murcia, Murcia, 1989.

EsPejo Arévalo Sebastiana, Eliodoro Puche, poeta lírico, Tesis de licenciatura, Universidad de Murcia, Murcia, 1964.

Fuentes Florido, Francisco (ed.), Poesías y poética del ultraísmo (Antología), Barcelona, Mitre, 1989.

Guerrero Ruiz, Pedro, Eliodoro Puche: paisaje y vuelo de un poeta, Consejo Municipal de Cultura y Festejos. Excmo. Ayuntamiento de Lorca. Murcia, 1994.

-. Homenaje a Eliodoro Puche, XIV aniversario de su muerte. Centro de Estudios Lorquinos. Lorca, 1978. 
Guirao, Juan y Molina, José Luis (eds.), Antología general. Eliodoro Puche, Editora Regional de Murcia. Murcia, 1983.

Molina, José Luis, Eliodoro Puche, entre la bohemia y el sentido humano de la vida, Concejalía de Cultura y Educación. Ayuntamiento de Lorca. Lorca, 1986.

Prada, Juan Manuel de, Desgarrados y excéntricos, Seix Barral, Barcelona, 2001.

Sarmiento, José Antonio y Barrera, José María (editores), Vltra, Visor, Madrid, 1993. 